\title{
Overweight induced by high-fat diet delays rat cutaneous wound healing
}

\author{
Adriana P. Nascimento and Andréa M. A. Costa* \\ Histology and Embryology Department, State University of Rio de Janeiro, Rua Professor Manuel de Abreu, 444, $3^{\circ}$ andar, \\ 20550-170, Rio de Janeiro, Brazil
}

(Received 28 April 2006 - Revised 20 July 2006 - Accepted 8 August 2006)

\begin{abstract}
Prolonged wound healing is a complication that contributes to morbidity and mortality. Overweight people regularly undergo surgery and trauma, and often develop chronic wounds, but the effects of the adipose tissue excess on cutaneous wound healing are not well understood. This study tested the hypothesis that overweight induced by a high-fat diet impairs rat cutaneous wound healing. Male Wistar rats were fed with either a highfat or a standard (control) diet. After 15 weeks, an excisional lesion was done and the animals were killed $21 \mathrm{~d}$ later. Wound contraction and reepithelialization, blood pressure, glucose and retroperitoneal fat were evaluated. After killing, lesion and adjacent normal skin were formol-fixed and paraffin-embedded. Inflammatory infiltrate, myofibroblasts, collagen fibres and cellular proliferation were analysed and blood vessels were evaluated using stereological methods. There was no difference in blood pressure and glucose, but retroperitoneal fat increased in the high-fat diet group. Animals fed with the high-fat diet presented delayed wound contraction and re-epithelialization. It was found that $21 \mathrm{~d}$ after wounding, overweight induced by a high-fat diet increased the inflammatory infiltrate and delayed myofibroblastic differentiation, collagen deposition, epithelial and connective tissue cell proliferation, and angiogenesis. These findings support the hypothesis that a high-fat diet exerts negative effects on rat cutaneous wound healing, due mainly to the prolongation of the inflammatory phase.
\end{abstract}

Wound healing: High-fat diet: Adipose tissue: Inflammation: Skin

Normal wound healing is a complex process involving a series of sequential and overlapping phases, including inflammation, granulation tissue formation and remodelling, which result in scar formation. This process requires interaction among a variety of cells, multiple cytokines and growth factors and extracellular matrix molecules. For normal wound healing, the temporal sequence of these events should be kept up, as it is necessary that the early events of coagulation and inflammation occur in a short time lapse and then cease to allow the subsequent reparative processes to occur (Singer \& Clark, 1999). Adipose tissue produces and secretes inflammatory cytokines (Mohamed-Ali et al. 1998; Sethi \& Hotamisligil, 1999) that, when in excess, can perpetuate the inflammation and delay the wound repair.

Over-consumption of a high-energy diet may contribute to positive energy balance and lead to overweight and obesity development (Swinburn \& Egger, 2002). Administration of a high-fat diet is an animal model that reproduces many features of human obesity (Lauterio et al. 1994). Rats fed a high-fat diet exhibit a bimodal pattern in body weight gain similar to that observed in human subjects (Lauterio et al. 1994) and the increase in body weight reflects an increase in adipose mass (Dobrian et al. 2000). Therefore, the main feature of obesity is the increase in adipose mass, and pathophysiology is the increased secretion of factors associated with enlarged fat cells (Bray, 2003).
White adipose tissue was traditionally considered as an energy storage cell. In recent years, we have become more aware that fat cells are metabolically active, producing adipokines, soluble hormone-like substances (including adiponectin and leptin) that have a wide range of metabolic effects (Rajala $\&$ Scherer, 2003). Targets of these mediators seem to include immune and inflammatory systems (Fantuzzi \& Faggioni, 2000; Rajala \& Scherer, 2003). White adipose tissue increase is associated with an increase in pro-inflammatory mediators such as TNF- $\alpha$ and various IL, including IL-1 $\beta$, IL-6 and IL-8 (Coppack, 2001; Grimble, 2002; Black, 2003; Dandona et al. 2004).

The effects of overweight on morbidity and mortality have been known for more than 2000 years (Bray, 2004). Overweight individuals often undergo surgery, experience trauma and develop chronic wounds (Wilson \& Clark, 2004). Providing wound care for an overweight patient requires an understanding of the intrinsic changes in body systems induced by an increase of adipose tissue mass and in particular the modifications induced in the woundhealing process. The aim of the present study was to investigate the effects of overweight induced by a high-fat diet on rat excisional cutaneous wound healing, evaluating wound contraction and re-epithelialization, inflammatory infiltrate, granulation tissue development and angiogenesis.

Abbreviations: PCNA, proliferating cell nuclear antigen; Vv, volume density.

*Corresponding author: Dr. Andréa Monte Alto Costa, fax +55 212587 6511, email amacosta@uerj.br 


\section{Material and methods}

\section{Animals and diets}

Male Wistar rats (120-150g) were randomly separated in control and diet groups. The control group ( $n$ 5) was fed with commercial pellets (Nuvital; Nuvilab ${ }^{\circledR}$, Colombo, PR, Brazil) and the diet group ( $n$ 15) was fed with a high-fat diet (containing 30\% fat) (Aoyama et al. 2000). The diet group contained more rats to accommodate the variability displayed by this group in weight gain. Animals were housed individually with free access to food and water throughout the experimental period. Table 1 shows the composition of the diets. All animal procedures were approved by the Animal Care and Use Committee of the Biology Institute of the State University of Rio de Janeiro.

Body weight was measured weekly from the beginning of experiment and naso-anal length was measured monthly. The systolic blood pressure was verified using the non-invasive method of the tail-cuff plethysmography in conscious rats (Letica LE 5100; Panlab, Barcelona, Spain) and the glucose was assessed with Accu-Chek (Roche Diagnostics, Mannheim, Germany) at the beginning and at 15 and 18 weeks of the experiment. Obesity Index of Lee was calculated monthly by dividing the cubic root of the body weight ( $\mathrm{g}$ ) by the nasoanal length $(\mathrm{mm}) \times 10^{4}$ (Cattaneo et al. 1997). All data are presented as means and standard deviations.

\section{Wounding procedure}

Since the pattern in body weight gain is bimodal in rats fed with a high-fat diet (Lauterio et al. 1994), at the 15th week of the diet the ten animals with greatest weight gain in the diet group were selected to continue the experiment. After 15 weeks of diet, on day 0 , the animals were anaesthetized with ketamine $(5 \mathrm{mg} / \mathrm{kg}$, intraperitoneally) and xylazine ( $2 \mathrm{mg} / \mathrm{kg}$, intraperitoneally), the dorsal surface was shaved and a full-thickness excisional wound $\left(4 \mathrm{~cm}^{2}\right)$ was made on the back of each rat by removing the skin (epidermis and dermis) and exposing paniculus carnosus. The wound was neither sutured nor covered and healed by second intension, as already described (Souza et al. 2005; Amadeu \& Costa, 2006).

Table 1. Experimental high-fat diet composition*

\begin{tabular}{lcc}
\hline Component (\%) & Standard & High-fat diet \\
\hline Commercial chow† & 100.0 & 60.0 \\
Condensed milk $\ddagger$ & & 15.0 \\
Shortening§ & & 25.0 \\
Protein (\%) & 23.0 & 15.0 \\
Fat (\%) & 6.0 & 30.0 \\
Carbohydrate (\%) & 71.0 & 55.0 \\
Energy (kJ/kg) & 18.0 & 23.0 \\
\hline
\end{tabular}

${ }^{\star}$ For details of diets and procedures, see p. 1070.

†Standard rat chow (Nuvital, Nuvilab ${ }^{\circledR}$, Colombo, PR, Brazil).

$\ddagger$ Nestlé ${ }^{\circledR}$, São Paulo, SP, Brazil.

$\S$ Primor $^{\circledR}$, Florianópolis, SC, Brazil. Shortening is a semisolid fat composed of hydrogenated soyabean oil, containing $30 \%$ trans fatty acids.

\section{Wound area}

To evaluate the wound contraction and re-epithelialization, its margins were traced on a transparent plastic sheet placed over it. Wound area was measured soon after injury and 7, 14 and 21 d later; re-epithelialized wound area was measured 14 and $21 \mathrm{~d}$ after wounding. Lesion tracings were digitalized and the wound area was evaluated using Image-Pro ${ }^{\circledR}$ Plus 5.0.2 image-processing program (Media Cybernetics, Silver Spring, MD, USA). Wound contraction was estimated by total lesion area and wound re-epithelialization was estimated by the difference between the total lesion area and the wound area still uncovered with epidermis, as shown in Fig. 1. Wound contraction data are expressed as a percentage of the initial wound area and re-epithelialization data are expressed as a percentage of re-epithelialized wound area at each measurement (means and standard deviations).

\section{Wound tissue processing and staining}

Rats were killed $21 \mathrm{~d}$ after injury (control group $n 5$ and diet group $n$ 10) in a $\mathrm{CO}_{2}$ chamber. The lesions and the adjacent skin were removed, formol-fixed and paraffin-embedded. Retroperitoneal fat was removed and weighed.

Sections $(5 \mu \mathrm{m})$ were stained with haematoxylin-eosin to analyse general aspects, inflammatory infiltrate and re-epithelialization; with Sirius Red for collagen fibre analysis; with $0.2 \%$ toluidine blue for mast cells evaluation.

The amount of polymorphonuclears was evaluated in haematoxylin-eosin-stained tissue sections. Ten random fields $\left(0.02 \mathrm{~mm}^{2}\right)$ were analysed using a $\times 100$ objective (Olympus CBA; Olympus Optical Co. Ltd, Tokyo, Japan) and the average cell count per field was calculated for each animal.

The number of mast cells was evaluated in toluidine bluestained tissue sections. Ten random fields $\left(0.12 \mathrm{~mm}^{2}\right)$ were analysed using a $\times 40$ objective (Olympus BH-2; Olympus Optical Co. Ltd) and the average cell count per field was calculated for each animal. The percentage of degranulating mast cells was also evaluated.

All analysis was done twice and blindly without any significant difference among measurements and data are expressed as means and standard deviations.

\section{Immunohistochemistry and quantification}

For assessment of myofibroblasts and blood vessels, a mouse monoclonal antibody against $\alpha$-smooth muscle actin (DAKO, Carpinteria, CA, USA) was used. Briefly, sections (5 $\mu \mathrm{m})$ were digested with $0.1 \%$ trypsin (Difco Laboratories, Detroit, MI, USA), incubated in $3 \% \mathrm{H}_{2} \mathrm{O}_{2}$ in methanol to block endogenous peroxidase activity and incubated with primary antibody. To localize proliferating cells, a mouse monoclonal antibody against the proliferating cell nuclear antigen (PCNA) (DAKO) was used. Briefly, sections were incubated in citrate buffer ( $\mathrm{pH}$ 6.0) for antigen retrieval, in $3 \% \mathrm{H}_{2} \mathrm{O}_{2}$ in methanol for endogenous peroxidase blocking and then with primary antibody. For revelation EnVision system ${ }^{\circledR}$ (DAKO) was used for both primary antibodies. Diaminobenzidine was used as chromogen and the nuclei were stained with Delafield's haematoxylin. Negative controls were performed 


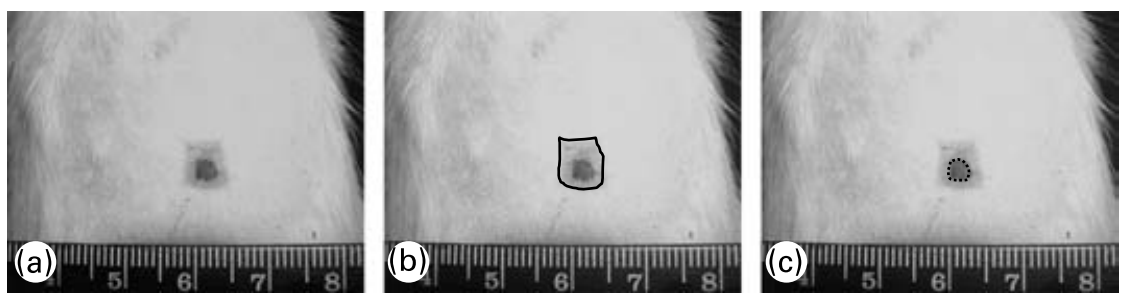

Fig. 1. Evaluation of wound contraction and re-epithelialization. (a) Original photo of wound area; (b) - shows total wound area; (c) --- shows non re-epithelialized wound area (still uncovered by a neo-epidermis). The difference between the two areas represents the re-epithelialized wound area.

replacing primary antibody by non-immune serum and no labelling was observed.

The distribution of blood vessels and myofibroblasts (expressing $\alpha$-smooth muscle actin) in the granulation tissue was evaluated by a stereological method (test system with cycloid arcs). Blood vessels were identified by the presence of smooth muscle cells expressing $\alpha$-smooth muscle actin in the wall and by the presence of blood cells in the lumen (Amadeu \& Costa, 2006). Since stereological methods are precise tools for obtaining information about three-dimensional structures based mainly on observations made in two-dimensional sections (Baddeley et al. 1986; Gundersen et al. 1988), the quantitative distribution of myofibroblasts and of superficial and deep vessels was evaluated using this method. To distribution of myofibroblasts, ten random fields were analysed in granulation tissue in each specimen using a $\times 40$ objective and to evaluate the distribution of blood vessels, eight random fields were analysed in superficial and deep regions of granulation tissue using a $\times 20$ objective. For assessment, a videomicroscopic system (Axiophot ZEISS microscope, JVC video-camera and Sony Trinitron monitor; Sony, Pencoed, UK) was used. The test system was displayed on the screen of the monitor and calibrated with a micrometer. Volume density (Vv), surface density and length density were estimated in both superficial and deep regions. $\mathrm{Vv}_{v}$, surface density and length density results are shown as means and standard deviations.

The number of PCNA-positive cell nuclei was counted in neo-epidermis and granulation tissue. In neo-epidermis, all basal cells were counted and the result is expressed as a percentage of PCNA-positive basal cells. In granulation tissue, ten random fields were counted with a $\times 40$ objective using a two-dimensional test frame area of $3.636 \mu \mathrm{m}^{2}$ and data are expressed as PCNA-positive cells $/ \mathrm{mm}^{2}$ in the granulation tissue. For counting, a video-microscopic system (Axiophot ZEISS microscope, JVC video-camera, and Sony Trinitron monitor) was used. The data are expressed as means and standard deviations. All analysis was done twice and blindly without significant difference among measurements.

\section{Statistical analysis}

One-way ANOVA with Tukey post test was used to analyse body weight. Unpaired $t$ test Welch corrected was used to analyse retroperitoneal fat, glucose, blood pressure, lesion area, inflammatory cells and cellular proliferation. Non-parametric Mann-Whitney test was used to analyse mast cells, myofibroblasts and blood vessel stereology. The software Graph Pad
Instat version 3.01 (GraphPad Software Inc., San Diego, CA, USA) was used and values of $P<0.05$ were considered statistically significant.

\section{Results}

Body weight, fat depot, blood pressure and glucose

Rats fed with a high-fat diet exhibit a bimodal pattern in body weight gain similar to that observed in man. Two-thirds of the rats gained weight rapidly when compared with chow-fed rats, whereas one-third gained body weight at a rate similar to that of the chow-fed animals. This model allows us to dissociate the factors related to a high-fat diet and increased body fat content (Lauterio et al. 1994). For this reason, the ten animals with the greatest weight gain after 15 weeks of diet were selected to continue the experiment.

The initial mean body weight of the groups did not present a difference between them (139.2 (SD 7.2) $\mathrm{g}$ in control and 141.7 (SD 5.3) $\mathrm{g}$ in the diet groups). At week 3 , the diet group had significantly higher $(P<0.05)$ body weight than the control group and the body weight remained higher throughout the 18 -week dietary period. On the day the lesion was performed (day 0), body weight was $25.7 \%$ higher in the diet group when compared with the control group and $18.6 \% 21 \mathrm{~d}$ after wounding $(P<0.001$ for both) (Fig. 2(a)). In terms of body weight gain, in the diet group it was significantly greater than in the control group (249.1 (SD 21.1) g v. 190.3 (SD 15.7) g; $P<0.001)$. Retroperitoneal fat mass was higher in the diet group when compared with the control group after 18 weeks of diet (10.3 (SD 1.9) g v. 2 (SD 0.7) g; $P<0.0001)$ (Fig. 2(b)). The high-fat diet caused a 5-fold increase in the amount of retroperitoneal fat. The Obesity Index of Lee (the equivalent of BMI for human subjects) significantly increased in the diet group 4 weeks after the beginning of the diet and it was still higher at $15(6.9 \% ; P<0.001)$ and at $18(5 \%$; $P<0.05)$ weeks after the beginning of the diet compared with the control group, reflecting the increased body fat content (Fig. 2(c)). Although the body weight of the diet group was greater, the animals were not obese. To be considered obese, animals should have a mean overweight of $57 \%$ (Cattaneo et al. 1997), but the rats presented a mean overweight of $18.6 \%$ after 18 weeks of the diet and as such they should be considered overweight (Cattaneo et al. 1997).

The baseline systolic blood pressure (106.2 (SD 4.3) $\mathrm{mmHg}$ in control and 106.3 ( $\mathrm{SD} \mathrm{4.5)} \mathrm{mmHg}$ in the diet group) and blood concentration of glucose $(6 \cdot 5$ (SD 0.2$) \mathrm{mmol} / \mathrm{l}$ in control and $6.8(\mathrm{SD} 0.3) \mathrm{mmol} / \mathrm{l}$ in the diet group) were not different between the two groups throughout the experiment, indicating 
(a)

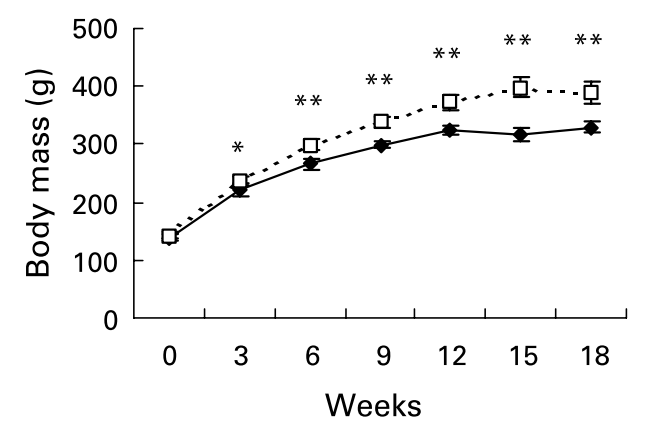

(b)

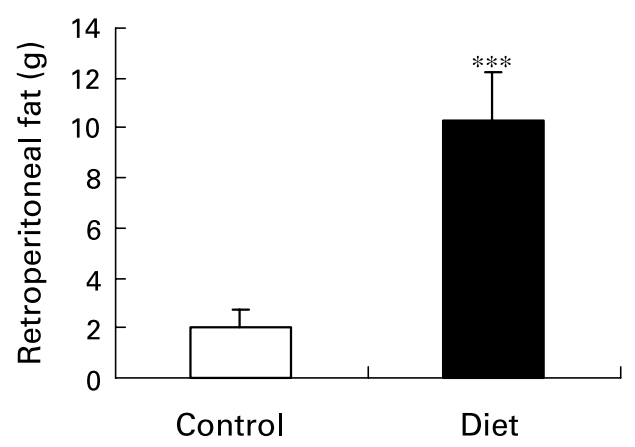

(c)

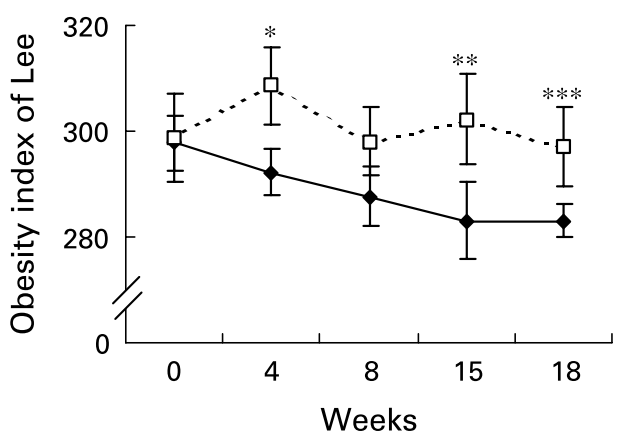

Fig. 2. Evaluation of body and of retroperitoneal fat mass. Mean values and standard deviations for five animals in the control group and ten animals in the diet group. For details of diets and procedures, see p. 1070. (a) Changes in body weight over 18 weeks on diets (- - , control; - - - - - -, diet group). Mean values were significantly higher than those for the control group after 3 weeks of diet: ${ }^{*} P<0.05 ;{ }^{* *} P<0.001$. (one-way ANOVA with Tukey post test). (b) Retroperitoneal fat mass after 18 weeks of diet. The high-fat diet promoted an increase in retroperitoneal fat depot. Mean value was significantly different from that of the control group: ${ }^{* \star *} P<0.0001$. (unpaired $t$ test Welch corrected). (c) Comparison of obesity index. The diet group (- - - $\square-$ - -) presented an increased index after 4, 15 and 18 weeks of diet. Mean values were significantly higher than those for the control group: ${ }^{\star} P<0.05$, ${ }^{* *} P<0.01,{ }^{* * *} P<0.001$. (- - , control group). (one-way ANOVA with Tukey post test).

that the high-fat diet did not induce the development of hypertension nor diabetes.

\section{Wound contraction and re-epithelialization}

Rats are loose-skinned animals, with the wound healing occurring primarily by first wound contraction and then by re-epithelialization via keratinocyte migration and proliferation
(Davidson, 1998). The control and diet groups presented a progressive reduction in wound area during the experiment. It was found that $14 \mathrm{~d}$ after wounding, the wound area in the diet group was $19 \%(P<0.05)$, higher than in the control group and $32 \%$ $(P<0.01)$ higher at $21 \mathrm{~d}$ after wounding, indicating less contraction (Fig. 3(a)).

Neo-epidermis formation progressively covered the wound area. The re-epithelialization was not complete in both groups $21 \mathrm{~d}$ after wounding. The re-epithelialization rate was $40 \%(P<0.0001)$ smaller in the diet group when compared with the control group and 14 and $11 \%(P<0.05)$ smaller $21 \mathrm{~d}$ after wounding (Fig. 3(b)), thus showing a delayed keratinocyte migration in rats fed a high-fat diet.

Epithelial cell proliferation was smaller in the control group when compared with the diet group $21 \mathrm{~d}$ after wounding (Fig. 4(a)). In the control group, PCNA-positive cells were limited to basal layer (Fig. 4(b)) and in the diet group PCNA-positive cells were also found in supra-basal layers (Fig. 4(c)). This result shows that in the diet group the epithelial cells were still in intense proliferation $21 \mathrm{~d}$ after wounding, but the small rate of re-epithelialization is probably due to a disturbance in keratinocyte migration.

\section{Inflammatory infiltrate and granulation tissue formation}

It was found that $21 \mathrm{~d}$ after wounding, the control group presented a small amount of inflammatory cells in the wound area

(a)
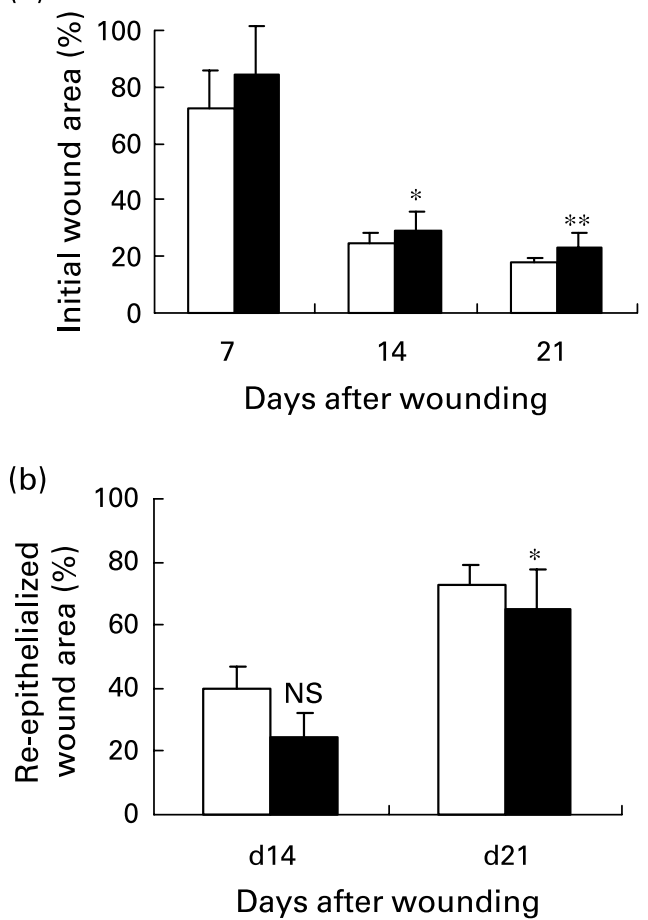

Fig. 3. Evaluation of wound contraction and formation of neo-epidermis in control ( $\square$ ) and diet ( $\square$ ) groups. Mean values and standard deviations for five animals in the control group and ten animals in the diet group. For details of diets and procedures, see p. 1070. (a) Animals fed the high-fat diet presented delayed wound contraction. Mean values were significantly different from that of control: ${ }^{\star} P<0.05,{ }^{* \star} P<0.01$. (b) animals fed the high-fat diet presented delayed re-epithelialization. Mean values were significantly different from that of control: ${ }^{\star} P<0.05,{ }^{\star \star \star} P<0.0001$ (unpaired $t$ test Welch corrected). 
(a)

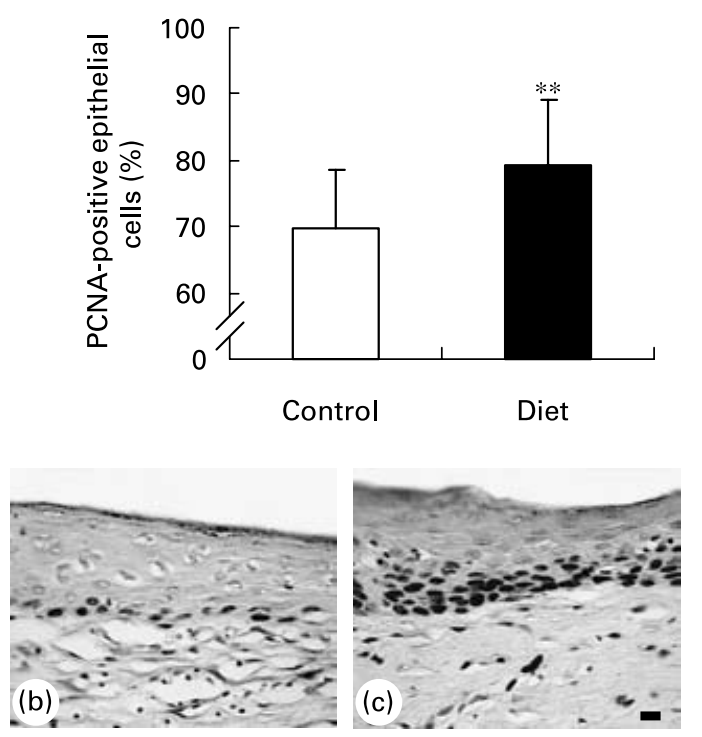

Fig. 4. (a) Percentage of proliferating cell nuclear antigen (PCNA)-positive basal epithelial cells in wound area of control and diet groups. Values are means and standard deviations. Bar $10 \mu \mathrm{m}$. For details of diets and procedures, see p. 1070. Mean value was significantly different from that of control: ${ }^{\star \star} P<0.01$ (unpaired $t$ test Welch corrected). Diet group (c) presented a larger number of proliferating cells in epidermal basal layer $21 \mathrm{~d}$ after wounding compared with control group (b).

and a greater amount of 'fibroblast-like' cells (Fig. 5(a)) when compared with the diet group (Fig. 5(b)). The diet group presented a higher amount of inflammatory cells localized mainly in the superficial area of lesion.

Quantification of polymorphonuclear leukocytes (Fig. 5(c)) in the wound area showed that $21 \mathrm{~d}$ after wounding the amount of polymorphonuclear leukocytes was smaller in the control group than in the diet group. This suggests that wound healing is impaired in the diet group due to prolongation of the inflammatory phase.

In both groups, mast cells were localized mainly in the deep area of granulation tissue. The majority of them were ovoid and localized near to blood vessels. The amount of mast cells was not different $21 \mathrm{~d}$ after wounding comparing the control and the diet groups (data not shown). Concerning the percentage of degranulating mast cells, there was also no difference between the control and the diet groups (82 (SD 16) $\%$ and 92 (SD 10) \%).

The analysis of myofibroblast showed that the $\mathrm{Vv}$ of myofibroblast was smaller $(P<0 \cdot 0001)$ in the granulation tissue of the control (0.6 (SD 1.9) \%) compared with the diet group (4.6 (SD 5.1) \%) (Fig. 6(a)). It was found that $21 \mathrm{~d}$ after wounding, the $\mathrm{Vv}_{\mathrm{V}}$ of myofibroblast in the control group was reduced and limited in the lesion edges (Fig. 6(b)); the diet group still presented a larger amount of myofibroblasts with homogeneous distribution along the granulation tissue (Fig. 6(c)).

PCNA-positive connective tissue cells were homogeneously distributed in the wound area of the control and the diet group. Quantification of PCNA-positive connective tissue cells showed that the diet group presented a higher $(P<0.001)$ number of proliferating cells $21 \mathrm{~d}$ after wounding (Fig. 7(a)). It was found that $21 \mathrm{~d}$ after wounding, the control group (Fig. 7(b)) presented a small amount of connective tissue
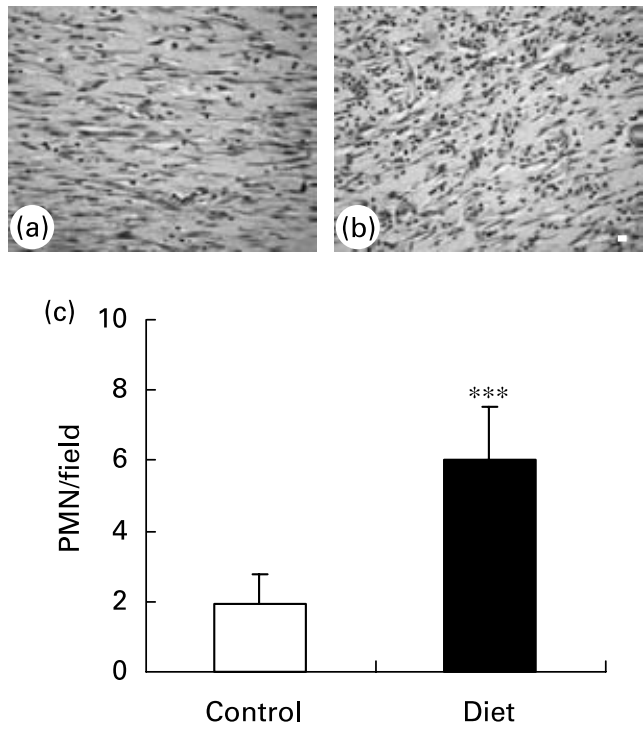

Fig. 5. Granulation tissue in (a) control and (b) diet groups $21 \mathrm{~d}$ after wounding. Distribution of inflammatory infiltrate in wound area. (a) Control group presented a high amount of fibroblastic cells in granulation tissue; (b) in diet group an increase in inflammatory infiltrated was observed. Bar $10 \mu \mathrm{m}$. (c) Quantification of polymorphonuclear (PMN) leukocytes/field in granulation tissue of control and diet groups. Mean values and standard deviations for five animals in the control group and ten animals in the diet group, ten fields were analysed in each animal. For details of diets and procedures, see p. 1070. Mean value was significantly different from that of the control group: ${ }^{\star \star \star} P<0.0001$ (unpaired $t$ test Welch corrected).
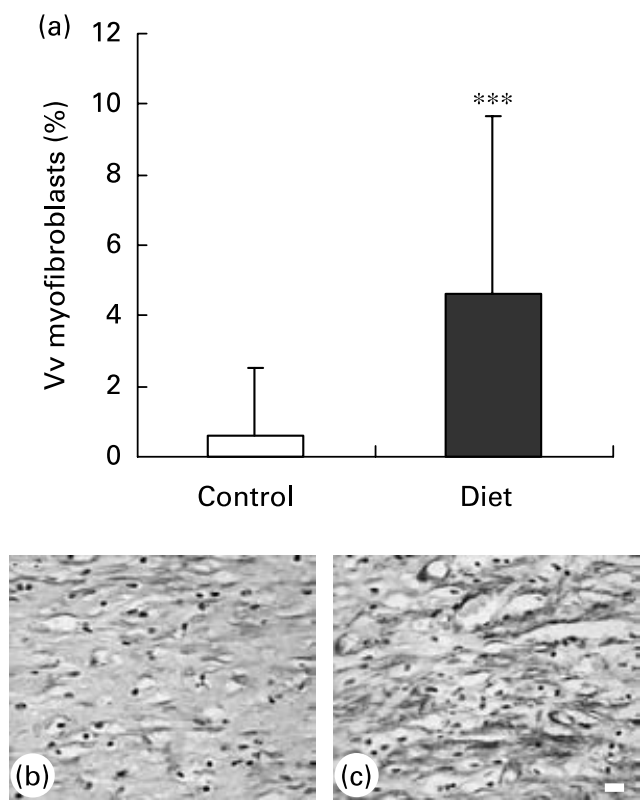

Fig. 6. Stereological analysis of $\alpha$-smooth muscle actin expressing cells in wound area of control and diet groups. (a) Volume density ( $\mathrm{Vv}$ ) of myofibroblasts in granulation tissue. Mean values and standard deviations for five animals in the control group and ten animals in the diet group. For details of diets and procedures, see p. 1070. Mean value was significantly different from that of the control group: ${ }^{\star \star \star} P<0.0001$ (Mann-Whitney test). Diet group (c) still presented a larger amount of myofibroblasts $21 \mathrm{~d}$ after wounding compared with control group (b). Bar $10 \mu \mathrm{m}$. 
proliferating cells compared with the diet group (Fig. 7(c)). This result indicates that lesions of animals fed a high-fat diet presented an intense proliferative response $21 \mathrm{~d}$ after wounding, a period when apoptosis occurs during normal wound repair, suggesting a delay in the proliferation of connective tissue cells.

Concerning collagen organization, $21 \mathrm{~d}$ after wounding the control group presented thick yellow-red collagen fibres arranged similarly to normal skin in the superficial and deep regions of the granulation tissue; the diet group showed a prevalence of thick red-yellow collagen fibres in the edge of the lesion and a lower amount of collagen fibres in the centre, always parallel to surface. The density of collagen fibres was higher in the control group than in the diet group and this indicates a delay in the synthesis and remodelling of extracellular matrix in the high-fat diet group (data not shown).

\section{Neovascularization of the granulation tissue}

The Vv of vessels was calculated to evaluate the volume occupied by vessels in both groups (Fig. 8(a)). In the diet group, the $\mathrm{Vv}$ of blood vessels was higher in both superficial and deep regions of the granulation tissue $21 \mathrm{~d}$ after wounding, when compared with those of the control group. The volume occupied by vessels in the diet group was $55 \%(P<0.05)$ higher in the superficial region and $70 \%(P<0 \cdot 01)$ higher in the deep region when compared with those of the control group (Fig. 8(a)).

The surface density of vessels was calculated to determine the surface occupied by vessels in both groups (Fig. 8(b)). An increase in the surface density of vessels indicates that

(a)

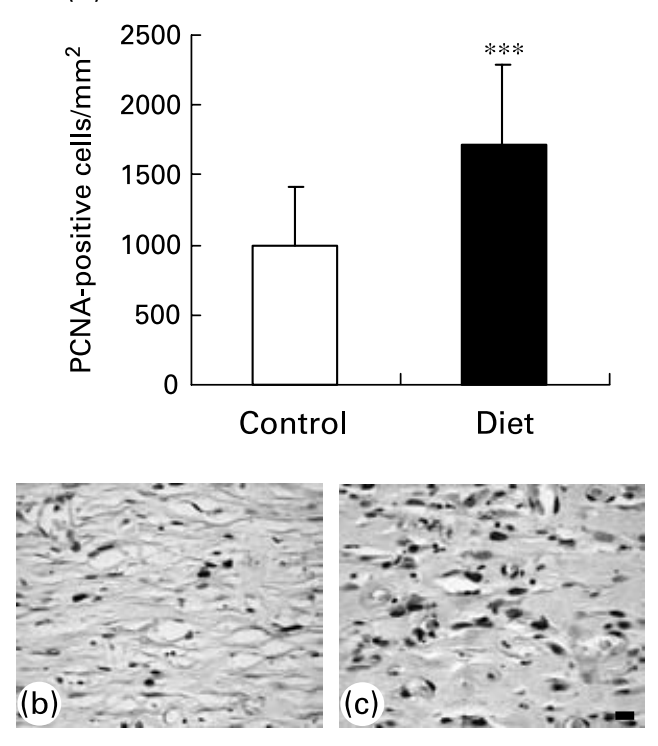

Fig. 7. (a) Number of proliferating cell nuclear antigen (PCNA)-positive connective tissue cells $/ \mathrm{mm}^{2}$ in wound area. Mean values and standard deviations for five animals in the control group and ten animals in the diet group, ten fields were analysed in each animal. For details of diets and procedures, see p. 1070. Mean value was significantly different from that of the control group: ${ }^{* \star *} P<0.0001$ (unpaired $t$ test Welch corrected). Control group (b) presented smaller amount of proliferating cells in granulation tissue than diet group (c). Bar $10 \mu \mathrm{m}$. they are dilated. In the diet group, the surface occupied by vessels was higher than in the control group $21 \mathrm{~d}$ after wounding. The comparison of the control and diet groups showed an
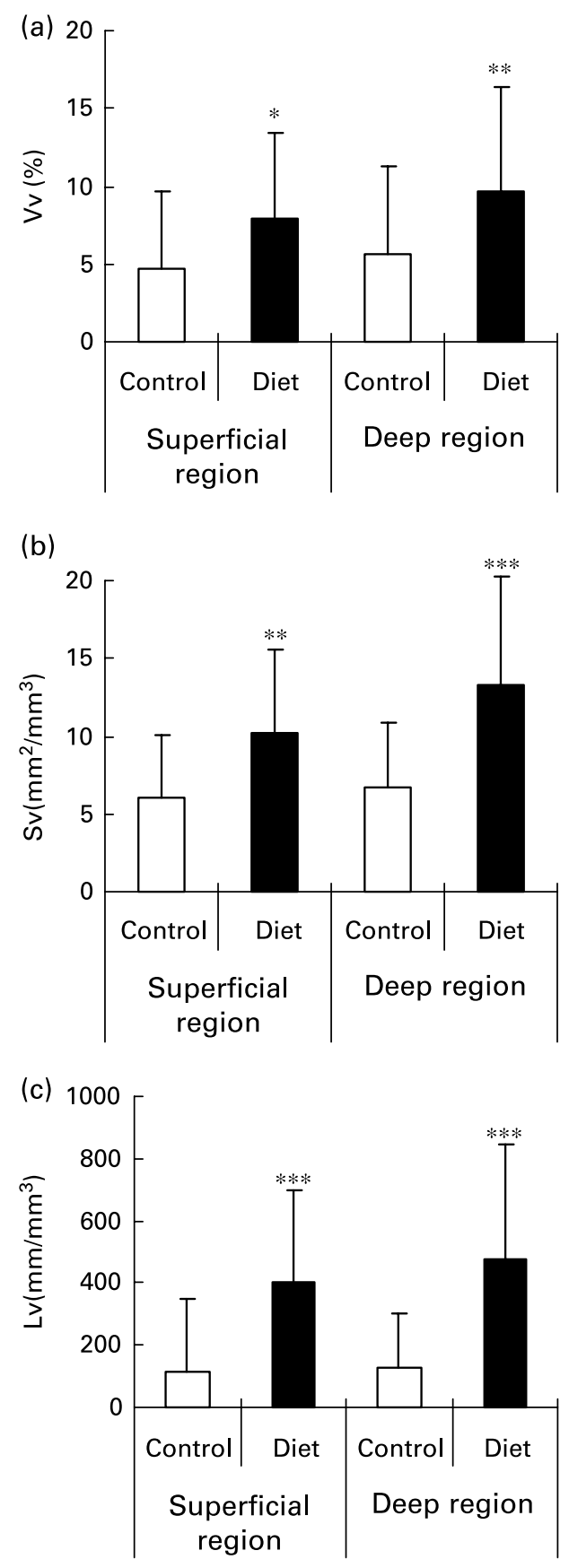

Fig. 8. Stereological analysis of blood vessels $21 \mathrm{~d}$ after wounding in control and diet groups. Mean values and standard deviations for five animals in the control group and ten animals in the diet group, sixteen fields were analysed in each animal (eight in superficial region and eight in deep region). For details of animals and procedures, see p. 1070. (a) Volume density (Vv). Mean value was significantly different from that of control in superficial region: ${ }^{*} P<0.05$. Mean value was significantly different from that of control in deep region: ${ }^{\star *} P<0 \cdot 01$. (b) Surface density (Sv). Mean value was significantly different from that of control in superficial region: ${ }^{\star \star} P<0 \cdot 01$. Mean value was significantly different from that of control in deep region: ${ }^{\star \star \star} P<0.001$. (c) Length density (Lv). Mean values were significantly different from those of the control group in superficial and deep region: ${ }^{* \star *} P<0.0001$ (Mann-Whitney test). 
increase of $54 \%(P<0 \cdot 01)$ of the surface occupied by vessels in the superficial region and $84 \%(P<0.001)$ in the deep region of the diet group (Fig. 8(b)).

The length density was used to indicate the winding of blood vessels (Fig. 8(c)). The length density of blood vessels increased in both the superficial and deep regions of the granulation tissue of the diet group when compared with the control group. The winding of blood vessels was $217 \%$ $(P<0.0001)$ higher in the superficial region and $277 \%$ $(P<0.0001)$ higher in the deep region $21 \mathrm{~d}$ after wounding in the diet group, when compared with the control group (Fig. 8(c)).

The present result shows that $21 \mathrm{~d}$ after wounding there is still a great amount of blood vessels in the granulation tissue of the diet group, indicating a delay in healing maturation.

\section{Discussion}

In the present study, overweight was induced by a high-fat diet in Wistar rats and its effects were investigated on wound contraction, re-epithelialization, inflammatory infiltrate, granulation tissue formation and neovascularization. Our study showed that overweight impairs excisional cutaneous wound healing by delaying wound contraction, re-epithelialization and granulation tissue formation by increasing the duration of inflammatory phase and by disturbing neovascularization and vessel morphology.

Overweight and obesity are problems of epidemic proportions (World Health Organization, 2002) and are associated with the increased incidence of many chronic diseases (Burton et al. 1985) and chronic wounds (Wilson \& Clark, 2004). Moreover, overweight is also associated with a variety of dermatoses (Khimich, 1997; Dowling et al. 2001; Hills et al. 2001; Kiess et al. 2001). The increased body mass reflects an increase in the adipose mass as evidenced by the increase in the obesity index and in the retroperitoneal fat mass. The present data agree with a previous study (Dobrian et al. 2000) that showed that, similar to human subjects, not all rats fed with a high-fat diet became overweight. Rats submitted to a high-fat diet present a bimodal distribution in body mass, that is, not all animals became overweight. The animals in the present study were not obese, neither did they present hypertension, contradicting data presented in previous studies (Aoyama et al. 2000; Barnes et al. 2003). This difference can be related to the start time of the high-fat diet (Hirsch, 1972); in the present study, the diet started $40 \mathrm{~d}$ after birth and in the study of Aoyama et al. (2000) the diet started soon after weaning ( $21 \mathrm{~d}$ after birth). Obesity has been positively correlated with changes in the cardiovascular system leading to the development of hypertension (Zhang et al. 2002). However, the mechanism by which obesity and hypertension are linked is still a question of great discussion. In the present work, our animals did not develop hypertension probably because they were not obese and a high-fat diet also did not induce diabetes. This result agrees with the literature in which high-fat feeding led to insulin resistance but not to diabetes in Wistar rats (Chalkley et al. 2002).

Re-epithelialization begins just after injury. At the beginning, keratinocytes migrate rather than proliferate to resurface the epidermal defect; when neo-epidermis is complete, keratinocytes proliferate to reconstruct the epidermis (Metze \& Luger, 2001). Overweight, induced by a high-fat diet, impaired re-epithelialization, mainly inhibiting keratinocyte migration, since the diet group presented a small re-epithelialized wound area, with an increase in the amount of proliferating keratinocytes in basal and supra-basal layers. Leptin is an adipocyte-derived polypeptide hormone (Ahima \& Flier, 2000) and its secretion is directly proportional to the adipose tissue mass (Fain et al. 2004). Recently, it was shown that leptin is a strong mediator of keratinocyte proliferation during wound healing in vivo (Frank et al. 2000) and this allows us to suggest that adipose tissue enlargement and the consequent increase in leptin concentration may lead to an increase in keratinocyte proliferation.

In rodents, wound contraction is the main mechanism of wound closure (Davidson, 1998). The present data showed a reduction in wound contraction 14 and $21 \mathrm{~d}$ after wounding in animals fed with a high-fat diet. Adipose tissue excess has been viewed as an inductor of the inflammatory process (Dandona et al. 1998; Grimble, 2002; Black, 2003) and recent attention has been focused on cytokines such as TNF$\alpha$ and IL6 (Chan et al. 2002). Although inflammation is important to induce myofibroblastic differentiation, the high degree of inflammation disturbs myofibroblastic differentiation. Therefore, it may be speculated that impaired wound contraction induced by overweight may be related to an increased inflammatory phase and to a delayed myofibroblastic differentiation caused by adipose tissue-derived pro-inflammatory cytokines.

During the early phases of wound healing, inflammatory cells are important in tissue debridement and bacterial killing and also because they release several cytokines and growth factors. While cytokines and growth factors seem to be necessary for wounds to heal, an excessive amount of inflammatory cytokines were detected in non-healing wounds (Garner et al. 1993; Cooney et al. 1997; Trengove et al. 2000). In this study, overweight increased inflammatory infiltrate in wound area. Overweight is associated with a chronic, low grade pro-inflammatory state as indicated by leukocytosis (Perfetto et al. 2002), increased plasma levels of pro-inflammatory cytokines (IL-6 (Yudkin et al. 2000) and TNF- $\alpha$ (Dandona et al. 1998)), C-reactive protein and acute phase proteins (Visser et al. 1999; van Dielen et al. 2001). Overweight is also associated with increased levels of endothelial cell dysfunction and activation markers (Ferri et al. 1999). The stimuli for cytokine production are not known, but it is assumed that the TNF- $\alpha$ in chronic low-grade systemic inflammation originates in the adipose tissue (Coppack, 2001). These findings may explain the increase, $21 \mathrm{~d}$ after wounding, of the infiltration of polymorphonuclear leukocytes observed in the diet group.

In granulation tissue formation, the myofibroblast differentiation is important since myofibroblasts are responsible for extracellular matrix deposition and wound contraction (Gabbiani, 2003; Desmouliere et al. 2005). It was found that $21 \mathrm{~d}$ after wounding, a high-fat diet increased myofibroblastic $\mathrm{Vv}$, but decreased collagen fibre density and organization. This suggests that myofibroblastic differentiation was delayed, also delaying extracellular matrix deposition. Therefore, adipose tissue excess probably delays myofibroblastic differentiation due to the prolongation of the inflammatory phase. 
Angiogenesis is closely related to the formation of granulation tissue. It depends on the interaction of multiple factors, such as vascular endothelial growth factor produced by a variety of cells (Dvorak et al. 1995; Mick et al. 2002; Silha et al. 2005). Conversely, angiogenesis has to cease when the wound defect is filled with granulation tissue. These sequential events reflect temporal changes in the balance between proangiogenic and anti-angiogenic factors. The present data have shown that $21 \mathrm{~d}$ after wounding the increase of the adipose tissue by a high-fat diet increased the volume occupied by blood vessels in superficial and deep regions of granulation tissue. These alterations may be explained by the increase of leptin levels, a circulating hormone secreted by adipocytes in quantities directly proportional to the adipose tissue mass (Fain et al. 2004). Leptin has been implicated in stimulation of angiogenesis (Bouloumie et al. 1998; Sierra-Honigmann et al. 1998).

In summary, the current study demonstrated that overweight induced by a high-fat diet exerts negative effects on rat cutaneous wound healing, mainly due to prolongation of the inflammatory phase. The present data showed that a high-fat diet impairs wound contraction and re-epithelialization, increases inflammatory cell migration and delays myofibroblastic differentiation, collagen deposition, epithelial and connective cell proliferation and angiogenesis. Therefore, it is important not only to pay attention to the nutritional status of the patients, but also to the quality of the diet, since both can interfere in the wound-healing process.

\section{Acknowledgements}

This study was partially supported by CNPq and FAPERJ. A.P. Nascimento holds a postgraduate fellowship from CNPq.

\section{References}

Ahima RS \& Flier JS (2000) Leptin. Annu Rev Physiol 62, 413-437. Amadeu TP \& Costa AMA (2006) Nitric oxide synthesis inhibition alters rat cutaneous wound healing. J Cutan Pathol 33, 465-473.

Aoyama T, Fukui K, Takamatsu K, Hashimoto Y \& Yamamoto T (2000) Soy protein isolate and its hydrolysate reduce body fat of dietary obese rats and genetically obese mice (yellow KK). Nutrition 16, 349-354.

Baddeley AJ, Gundersen HJ \& Cruz-Orive LM (1986) Estimation of surface area from vertical sections. J Microsc 142(Pt 3), 259-276.

Barnes MJ, Lapanowski K, Conley A, Rafols JA, Jen KL \& Dunbar JC (2003) High fat feeding is associated with increased blood pressure, sympathetic nerve activity and hypothalamic mu opioid receptors. Brain Res Bull 61, 511-519.

Black PH (2003) The inflammatory response is an integral part of the stress response: Implications for atherosclerosis, insulin resistance, type II diabetes and metabolic syndrome X. Brain Behav Immun 17, 350-364.

Bouloumie A, Drexler HC, Lafontan M \& Busse R (1998) Leptin, the product of $\mathrm{Ob}$ gene, promotes angiogenesis. Circ Res 83, 1059-1066.

Bray GA (2003) An Atlas of Obesity and Weight Control. London: Parthenon Publishing.

Bray GA (2004) Medical consequences of obesity. J Clin Endocrinol Metab 89, 2583-2589.
Burton BT, Foster WR, Hirsch J \& Van Itallie TB (1985) Health implications of obesity: an NIH Consensus Development Conference. Int J Obes 9, 155-170.

Cattaneo L, De Gennaro Colonna V, Zoli M, Muller EE \& Cocchi D (1997) Hypothalamo-pituitary-IGF-1 axis in female rats made obese by overfeeding. Life Sci 61, 881-889.

Chalkley SM, Hettiarachchi M, Chisholm DJ \& Kraegen EW (2002) Long-term high-fat feeding leads to severe insulin resistance but not diabetes in Wistar rats. Am J Physiol Endocrinol Metab 282, E1231-E1238.

Chan JC, Cheung JC, Stehouwer CD, Emeis JJ, Tong PC, Ko GT \& Yudkin JS (2002) The central roles of obesity-associated dyslipidaemia, endothelial activation and cytokines in the metabolic syndrome-an analysis by structural equation modelling. Int $J$ Obes Relat Metab Disord 26, 994-1008.

Cooney R, Iocono J, Maish G, Smith JS \& Ehrlich P (1997) Tumor necrosis factor mediates impaired wound healing in chronic abdominal sepsis. J Trauma 42, 415-420.

Coppack SW (2001) Pro-inflammatory cytokines and adipose tissue. Proc Nutr Soc 60, 349-356.

Dandona P, Aljada A \& Bandyopadhyay A (2004) Inflammation: the link between insulin resistance, obesity and diabetes. Trends Immunol 25, 4-7.

Dandona P, Weinstock R, Thusu K, Abdel-Rahman E, Aljada A \& Wadden T (1998) Tumor necrosis factor-alpha in sera of obese patients: fall with weight loss. J Clin Endocrinol Metab 83, 2907-2910.

Davidson JM (1998) Animal models for wound repair. Arch Dermatol Res 290, Suppl., S1-S11.

Desmouliere A, Chaponnier C \& Gabbiani G (2005) Tissue repair, contraction, and the myofibroblast. Wound Repair Regen 13, 7-12.

Dobrian AD, Davies MJ, Prewitt RL \& Lauterio TJ (2000) Development of hypertension in a rat model of diet-induced obesity. Hypertension 35, 1009-1015.

Dowling AM, Steele JR \& Baur LA (2001) Does obesity influence foot structure and plantar pressure patterns in prepubescent children? Int J Obes Relat Metab Disord 25, 845-852.

Dvorak HF, Detmar M, Claffey KP, Nagy JA, van de Water L \& Senger DR (1995) Vascular permeability factor/vascular endothelial growth factor: an important mediator of angiogenesis in malignancy and inflammation. Int Arch Allergy Immunol 107, 233-235.

Fain JN, Madan AK, Hiler ML, Cheema P \& Bahouth SW (2004) Comparison of the release of adipokines by adipose tissue, adipose tissue matrix, and adipocytes from visceral and subcutaneous abdominal adipose tissues of obese humans. Endocrinology 145, 2273-2282.

Fantuzzi G \& Faggioni R (2000) Leptin in the regulation of immunity, inflammation, and hematopoiesis. J Leukoc Biol 68, 437-446.

Ferri C, Desideri G, Valenti M, Bellini C, Pasin M, Santucci A \& De Mattia G (1999) Early upregulation of endothelial adhesion molecules in obese hypertensive men. Hypertension 34, 568-573.

Frank S, Stallmeyer B, Kampfer H, Kolb N \& Pfeilschifter J (2000) Leptin enhances wound re-epithelialization and constitutes a direct function of leptin in skin repair. J Clin Invest 106, 501-509.

Gabbiani G (2003) The myofibroblast in wound healing and fibrocontractive diseases. J Pathol 200, 500-503.

Garner WL, Karmiol S, Rodriguez JL, Smith DJ Jr \& Phan SH (1993) Phenotypic differences in cytokine responsiveness of hypertrophic scar versus normal dermal fibroblasts. J Invest Dermatol 101, $875-879$.

Grimble RF (2002) Inflammatory status and insulin resistance. Curr Opin Clin Nutr Metab Care 5, 551-559.

Gundersen HJ, Bendtsen TF, Korbo L, et al. (1988) Some new, simple and efficient stereological methods and their use in pathological research and diagnosis. Apmis 96, 379-394.

Hills AP, Hennig EM, McDonald M \& Bar-Or O (2001) Plantar pressure differences between obese and non-obese adults: a biomechanical analysis. Int J Obes Relat Metab Disord 25, 1674-1679. 
Hirsch J (1972) Can we modify the number of adipose cells? Postgrad Med 51, 83-86.

Khimich S (1997) Level of sensitivity of pain in patients with obesity. Acta Chir Hung 36, 166-167.

Kiess W, Galler A, Reich A, Muller G, Kapellen T, Deutscher J, Raile K \& Kratzsch J (2001) Clinical aspects of obesity in childhood and adolescence. Obes Rev 2, 29-36.

Lauterio TJ, Bond JP \& Ulman EA (1994) Development and characterization of a purified diet to identify obesity-susceptible and resistant rat populations. J Nutr 124, 2172-2178.

Metze D \& Luger T (2001) The Biology of the Skin. New York: Parthenon Publishing.

Mick GJ, Wang X \& McCormick K (2002) White adipocyte vascular endothelial growth factor: regulation by insulin. Endocrinology 143, 948-953.

Mohamed-Ali V, Pinkney JH \& Coppack SW (1998) Adipose tissue as an endocrine and paracrine organ. Int J Obes Relat Metab Disord 22, 1145-1158.

Perfetto F, Mancuso F \& Tarquini R (2002) Leukocytosis and hyperleptinemia in obesity: is there a link? Haematologica 87, ELT25.

Rajala MW \& Scherer PE (2003) Minireview: the adipocyte-at the crossroads of energy homeostasis, inflammation, and atherosclerosis. Endocrinology 144, 3765-3773.

Sethi JK \& Hotamisligil GS (1999) The role of TNF alpha in adipocyte metabolism. Semin Cell Dev Biol 10, 19-29.

Sierra-Honigmann MR, Nath AK, Murakami C, et al. (1998) Biological action of leptin as an angiogenic factor. Science 281, 1683-1686.

Silha JV, Krsek M, Sucharda P \& Murphy LJ (2005) Angiogenic factors are elevated in overweight and obese individuals. Int $J$ Obes (Lond) 29, 1308-1314.
Singer AJ \& Clark RA (1999) Cutaneous wound healing. $N$ Engl $J$ Med 341, 738-746.

Souza BR, Cardoso JF, Amadeu TP, Desmouliere A \& Costa AM (2005) Sympathetic denervation accelerates wound contraction but delays reepithelialization in rats. Wound Repair Regen 13, $498-505$.

Swinburn B \& Egger G (2002) Preventive strategies against weight gain and obesity. Obes Rev 3, 289-301.

Trengove NJ, Bielefeldt-Ohmann H \& Stacey MC (2000) Mitogenic activity and cytokine levels in non-healing and healing chronic leg ulcers. Wound Repair Regen 8, 13-25.

van Dielen FM, van't Veer C, Schols AM, Soeters PB, Buurman WA \& Greve JW (2001) Increased leptin concentrations correlate with increased concentrations of inflammatory markers in morbidly obese individuals. Int J Obes Relat Metab Disord 25, 1759-1766.

Visser M, Bouter LM, McQuillan GM, Wener MH \& Harris TB (1999) Elevated C-reactive protein levels in overweight and obese adults. JAMA 282, 2131-2135.

Wilson JA \& Clark JJ (2004) Obesity: impediment to postsurgical wound healing. Adv Skin Wound Care 17, 426-432.

World Health Organization (2002) The World Report 2002: Reducing Risks, Promoting a Healthy Life. Geneva, Switzerland: WHO.

Yudkin JS, Kumari M, Humphries SE \& Mohamed-Ali V (2000) Inflammation, obesity, stress and coronary heart disease: is interleukin-6 the link? Atherosclerosis 148, 209-214.

Zhang R, Thakur V, Morse S \& Reisin E (2002) Renal and cardiovascular considerations for the nonpharmacological and pharmacological therapies of obesity-hypertension. J Hum Hypertens 16, 819-827. 